Recurrent incarceration and/or sacculation of the gravid uterus: A review Non Peer-reviewed author version

DIERICKX, Inge; Mesens, Tinne; Van Holsbeke, Caroline; MEYLAERTS, Liesbeth; Voets, Willy \& GYSELAERS, Wilfried (2010) Recurrent incarceration and/or sacculation of the gravid uterus: A review. In: Journal of Maternal-Fetal and Neonatal Medicine, 23(8). p. 776-780.

DOI: $10.3109 / 14767050903410680$

Handle: http://hdl.handle.net/1942/10677 


\title{
Recurrent incarceration and/or sacculation of the gravid uterus: review of the literature.
}

\author{
I. Dierickx ${ }^{1}$, W. Voets ${ }^{2}$, L. Meylaerts ${ }^{3}$, T. Mesens ${ }^{1}$, C. Van Holsbeke ${ }^{1}$, W. \\ Gyselaers ${ }^{1,4}$ \\ ${ }^{1}$ Department of Obstetrics and Gynecology, Ziekenhuis Oost Limburg, Genk, Belgium \\ 2 Department of Obstetrics and Gynecology, Salvator-St.-Ursula Ziekenhuis, Hasselt, Belgium \\ ${ }^{3}$ Departement of Medical Imaging, Ziekenhuis Oost Limburg, Genk, Belgium \\ ${ }^{4}$ Department of Physiology, Hasselt University, Diepenbeek Belgium.
}

Key words: uterine incarceration, uterine sacculation, retroverted uterus, prematurity, uterine manipulation

\section{Address for correspondence:}

Corresponding author: Inge Dierickx

Department of Obstetrics and Gynecology

Ziekenhuis Oost Limburg

Schiepse Bos 6

3600 Genk

Belgium

Telephone: + 32477694325

E-mail: inge.dierickx@hotmail.com 


\section{Abstract}

Retroverted uterine incarceration with sacculation of the anterior wall is reported to occur approximately in 1/3000 pregnancies. A literature search identified only 1 case report of incarceration of an anteflexed gravid uterus and 6 reported cases of recurrent incarceration and/or sacculation. We present a case of an incarceration of an anteflexed uterus in the first pregnancy, followed by a retroflexed incarceration in the second pregnancy. From this, a review is presented on recurrent uterine incarceration and/or sacculation. 


\section{Introduction}

Retroversion of the uterus is present in $15 \%$ of pregnancies during the first trimester, but the fundus usually enters the abdominal cavity by the end of the first trimester. Abdominal ascent of the pregnant uterus may be prevented by posterior-wall fibroids, adhesions, endometriosis, uterus anomalies or a deep sacral concavity with an overlying promontory [1,2]. Uterine incarceration, defined as intrapelvic locking of the uterine fundus during pregnancy, was first described by Hunter in 1771 [3]. It is estimated to occur in approximately 1 in 3000 pregnancies [4]. When pregnancy progresses, myometrial expansion of the incarcerated uterus occurs by (over)stretching or sacculation of the uterine anterior wall (Figure 1).

Some confusion exists because the terms diverticulum, sacculation and incarceration are often used interchangeably [5]. The classical or true sacculation is associated with a retroverted, often incarcerated, gravid uterus in which the saclike structure usually develops from the anterior wall of the uterus (Figure 1). Simple sacculation is a functional malformation during pregnancy containing all layers of the uterus and is unrelated to retroversion and incarceration. It can occur posteriorly, anteriorly or laterally, so no part of the uterus appears to be immune [5]. Many theories have tried to explain the cause of simple sacculation, but often there is no identifiable one [5,6]. 


\section{$\underline{\text { Materials and Methods }}$}

We performed a literature search on PubMed using the terms 'incarcerated uterus', 'incarceration' and 'sacculation'. We also searched the reference lists of the published articles. From the list of reported cases, we selected those reports on recurrence of uterine incarceration and/or sacculation. 


\section{$\underline{\text { Case report }}$}

A 34-year-old primigravida complained of mictalgia for some weeks in the first trimester of her twin pregancy. These symptoms resolved spontaneously. At 29 weeks, she was admitted to the Maternal-Fetal Medicine Unit of Ziekenhuis Oost Limburg, Genk Belgium, for preëclampsia and severe growth retardation of both siblings. Vaginal examination revealed a cervix located very deeply in the posterior fornix. Conservative treatment was initiated with methyldopa 3x250mg daily and induction of lung maturation with betamethasone 2x12mg. At 32 weeks she developed pulmonary oedema and renal failure. Two female infants, weighing 800 and 706 gram were delivered by caesarean section. The incarcerated uterus with anterior sacculation was only diagnosed peroperatively after delivery of the twins : the uterine incision was made on the posterior fundal wall. Both infants died of severe respiratory distress.

In her second pregnancy, two years later, she developed acute urinary retention at 18 weeks. Vaginal examination showed the uterus to be fixated in retroversion with the cervix highly anterior behind the symphysis. The fundal height was small for dates. The diagnosis of incarceration of uterus with posterior sacculation was confirmed by Magnetic Resonance Imaging (MRI) scan (Figure 2). The incarceration was restored by manual manipulation during colonoscopy-assisted insufflation of the rectosigmoid. In the third trimester, a growth retardation was diagnosed. At 37 weeks a caesarean section was performed for dysmaturity and corporeal uterine scar, with birth of a girl of 1820 gram in good condition. On inspection, the old uterine scar was healed without adhesions. 


\section{$\underline{\text { Discussion }}$}

We present a case of recurrent incarceration of the gravid uterus into opposite directions (Case 7, Table I). Five of six other reported cases of recurrent sacculation were caused by incarceration of a retroverted uterus $[2,7,8,9,10]$ and Minassian et al. reported the single case of recurrent sacculation without incarceration. [11].

Uterine anomalies are a well known risk factor for incarceration of the uterus [12]. In this review of recurrent incarceration, two patients had an uterus didelphys and one patient had an uterus bicornis. Other known risk factors are endometriosis, pelvic adhesions, uterine prolaps [13], fibroids on the posterior wall and a deep sacral concavity with an overlying promontorium $[2,7,14]$. The woman of our case report did not have any known risk factors.

Diagnosis of uterine incarceration remains difficult because of the very aspecific symptoms such as constipation, tenesmus, low abdominal or back pain, dysuria, urgency and urinary retention $[1,15]$. In retrospect, refractory urinary problems in the late first trimester of the pregnancy of our patient may have been related to the incarceration. In advanced gestational stages, complications such as intra-uterine growth retardation, prematurity and premature rupture of the membranes have been reported. Because the fundus does not participate in the growth of the uterus, the lower uterine segment stretches to accommodate the fetal growth (Figure 1). The pregnancy continues until the upper limit of this type of uterine growth, which often is before term. In this review, only 3/14 (21\%) of pregnancies ended at 37 weeks or more. In our patient, both pregnancies were complicated by severe growth retardation. Probably, compression of the uterine vessels and dysfunctional uterine blood supply may contribute to retarded

fetal growth and dysmaturity [1].

Diagnosis can be difficult and is based on clinical suspicion. Urinary frequency, urgency, retention or incontinence presenting during the early midtrimester should alert the clinician. 
At vaginal examination, a large mass can be felt in the cul-de-sac. The cervix usually is displaced anteriorly (or posteriorly) out of reach of the examining fingers and cannot be visualized during speculum examination.

Our patient had an anterior uterine incarceration in her first pregnancy. Anterior uterine incarceration has only been reported once by Hirsch [16]. In that case, uterine fixation was probably caused by restrictive adhesions, as a result of the patient's prior pregnancy termination and pelvic inflammatory disease. Cehelsky and Mason mentioned two cases of anterior uterine incarceration reported in the German literature from the $19^{\text {th }}$ century, which they interpreted to result from prior surgical ventral or vaginal fixation of the uterus [17]. The woman in our case did not have any such risk factors.

Despite the availability of sonography, a large number of reported sacculations were not recognized before term [18]. This was also true in the first pregnancy of our patient. When the cervix is elongated and wedged behind the symphysis, abdominal sonography is superior to transvaginal sonography in revealing the position of the cervix and its internal ostium and defining the relationships between the bladder, uterus and vagina [19]. Magnetic Resonance Imaging (MRI) appears to be the imaging method of choice [20,21]. Characteristic MRIfindings of a posterior incarceration is a "free-standing", T-shaped multi-layer myometrium on sagittal images and a small cleft-like cystic lesion between the bladder and the sacculation on axial images, corresponding to the stretched cervix and the caudal part of the uterus [10,19,20,21]. This is illustrated in Figure 2. Differential diagnosis from uterine torsion sometimes is difficult [22].

Most authors recommend an early aggressive treatment, because of the possible consequences on gestational outcome and because early recognition is the cornerstone of a successful treatment [4]. In order to achieve this, it has been advised to examine all women with known retroverted uterus during the twelfth week of pregnancy [6,9]. Whereas some authors 
recommend intervention only in symptomatic women [1,19], most others agree attempting to replace the uterus in its natural position as soon as possible after diagnosis. Repositioning of a retroverted uterus is most likely to be successful in early pregnancy. Attempts later than $20^{\text {th }}$ week are more likely to fail and may cause complications such as preterm labor and preterm rupture of membranes [23]. After catheterization of the bladder, reposition is made by gentle digital pressure on the uterine fundus in the posterior fornix of the vagina. Trendelenburg, knee-chest position and the use of a tenaculum may be helpful. Several authors advise to support the uterus by a pessary after successful reduction since re-incarceration may occur after successful reduction.

Colonoscopy-assisted reposition of the intercerated uterus during colonoscopic insufflation of the rectosigmoid at gestational age of 13-15 weeks has been reported by Seubert et al. [24]. When this procedure is performed by an experienced endoscopist, the risk of bowel perforation should not be higher than with diagnostic colonoscopy (2/1000) [25]. In our case, colonoscopy-assisted reposition was successful even at a rather late gestation of 20 weeks.

Operative reduction by laparoscopy or -tomy should only be considered when all interventions mentioned above have failed. Caesarean section by median laparotomy is advised in an irreducible incarcerated uterus at term $[6,18,26]$. In case of posterior incarceration, the bladder is stretched up to a much higher level than normal, which should be considered carefully at entrance of the abdominal cavity. When the uterus cannot be anteverted before hysterotomy [26], the incision must be made high to avoid damaging bladder, cervix or vagina. In our patient, the diagnosis of anteverted incarceration was made only after delivery of the twins, as the uterine incision accidentally was made on the posterior fundal wall. There are insufficient arguments to recommend an operative procedure during caesarean section to prevent recurrent incarceration in future pregnancies [6]. 
As mentioned above, there is only one report of recurrent uterine sacculation without incarceration [11]. Simple sacculation can already present in early pregnancy [27] and vaginal delivery has been reported [11]. Despite this, it is recommended to perform a caesarean section when uterine sacculation is diagnosed before delivery, because weakening of the sacculated part of the uterus may reach the stage of visual translucency [28] and spontaneous uterine rupture at 18 weeks of gestation has been reported [29]. 


\section{Conclusion}

We report a case of recurrent uterine incarceration into opposite directions. This is the single case report on this specific condition, as illustrated in the literature review presented in this paper.

Although uterine incarceration is a rare condition, lacking specific symptoms or signs, the obstetrician should consider it in case of clinical suspicion, in order to prevent late gestational complications or poor obstetric outcome. Early diagnosis is the cornerstone of a successful treatment. 


\section{$\underline{\text { Acknowledgements }}$}

The authors would like to thank Dr. Mieke Lauwers and Dr. Joke Bulthé for their valuable assistance in the preparation of this paper. 


\section{$\underline{\text { References }}$}

1. Lettieri L, Rodis JF, McLean DA, Campbell WA, Vintzileos AM. Incarceration of the gravid uterus. Obstet Gynecol Surv 1994;49(9):642-6.

2. Hooker AB, Bolte AC, Exalto N, Van Geijn HP. Recurrent incarceration of the gravid uterus. J Matern Fetal Neonatal Med 2009;22(5):462-464.

3. Longo LD. On retroversion of the uterus by William Hunter in Medical Observations Inquiry 4:388,1771. Am J Obstet Gynecol 1978;113:95-6.

4. Weekes AR, Atlay RD, Brown VA, Jordan EC, Murray SM. The retroverted gravid uterus and its effect on the outcome of pregnancy. BMJ 1976;1:622-624.

5. Weissberg SM, Gall SA. Sacculation of the pregnant uterus. Obstet Gynecol 1972;39(5):691-698.

6. Fadel HE, Misenhimer HR. Incarceration of the retroverted gravid uterus with sacculation. Obstet Gynecol 1974;43(1):46-49.

7. Wood PA, Blanchard ME, Traylor B, Hill NN, Kirkland JA, Glover JB. Posterior sacculation of the uterus in a patient with a double uterus. Am J Obstet Gynecol 1967;99:907908.

8. McGann KP, Griffin WT. Recurrent classical sacculation of the pregnant uterus. J Fam Pract 1987;26(3):339-341.

9. Jacobsson B, Wide-Swensson D. Recurrent incarceration of the retroverted gravid uterus a case report. Acta Obstet Gynecol Scand 1999;78:737-741.

10. Sutter R, Frauenfelder T, Marincek B, Zimmermann R. Recurrent posterior sacculation of the pregnant uterus and placenta increta. Clin Radiol 2006;61:527-530.

11. Minassian VA, Dunn M. Recurrent sacculation of the pregnant uterus. A case report. J Reprod Med 2000;45:1003-1006.

12. Singh M, Payappagoudar J, Lo J, Prashar S. Incarcerated retroverted uterus in the third trimester complicated by postpartum pulmonary embolism. Obstet Gynecol 2007;109:498501.

13. Özel B. Incarceration of a retroflexed, gravid uterus from severe uterine prolapse: a case report. J Reprod Med 2005;50(8):624-626.

14. Schwartz Z, Dgani R, Katz Z, Lancet M. Case report: Urinary retention caused by impaction of leiomyoma in pregnancy. Acta Obstet Gynecol Scand 1986;65:525-526.

15. Smalbraak I, Bleker OP, Schutte MF, Treffers PE. Incarceration of the retroverted gravid uterus: a report of four cases. Eur J Obstet Gynecol Reprod Biol 1991;39:151-155.

16. Hirsch E. Anterior uterine incarceration. Int J Gynaecol Obstet 1997;57(2):195-197

17. Cehelsky MR, Mason VC. Anterior sacculation of the pregnant uterus at term. Am J Obstet Gynecol 1967;99:1000-1005.

18. Renaud MC, Bazin S, Blanchet P. Asymptomatic uterine incarceration at term. Obstet Gynecol 1996;88:721.

19. Gottschalk EM, Siedentopf JP, Schoenborn I, Gartenschlaeger S, Dudenhausen JW, Henrich W. Prenatal sonographic and MRI findings in a pregnancy complicated by uterine sacculation: case report and review of the literature. Ultrasound Obstet Gynecol 2008;32:582586.

20. DeFriend DE, Dubbins PA, Hughes PM. Sacculation of the uterus and placenta accreta: MRI appearances. Br J Radiol 2000;73:1323-1325.

21. van Beekhuizen HJ, Bodewes HW, Tepe EM et al. Role of magnetic resonance imaging in the diagnosis of incarceration of the gravid uterus. Obstet Gynecol 2003;102(5Pt2):11341137.

22. Piccone O, Fubini A, Doumerc S, Frydman R. Cesarean delivery by posterior hysterotomy due to torsion of the pregnant uterus. Obstet Gynecol 2006;107:533-535. 
23. Jacobsson B, Wide-Swensson D. Incarceration of the retroverted gravid uterus-a review. Acta Obstet Gynecol Scand 1999;78:665-668.

24. Seubert DE, Puder KS, Goldmeier P, Gonik B. Colonoscopic release of the incarcerated gravid uterus. Obstet Gynecol 1999;94:792-794.

25. Gedebou TM, Wong RA, Rappaport ED, Jaffe P, Kahasi D, Hunter GC. Clinical presentation and management of iatrogenic colon perforations. Am J Surg 1996;172:454-457.

26. Evans AJ, Anthony J, Masson GM. Incarceration of the retroverted gravid uterus at term. Case report. Br J Obstet Gynaecol 1986;93:883-885.

27. Fields C, Pildes RB. Sacculation of the uterus. Am J Obstet Gynecol 1963;87:507-514.

28. Pierce JR. The etiology of diverticulum of the uterus in pregnancy. With report of a case. Am J Obstet Gynecol 1958;75:1279-1282.

29. Saha A, Bhargava VL. Ruptured uterine sacculation: a rare presentation of ectopic implantation. Acta Obstet Gynecol Scand 1988;67:751-753. 


\section{Figure Headings}

\section{Figure 1:}

Posterior uterine incarceration.

When pregnancy progresses, myometrial expansion of the incarcerated uterus occurs by (over)stretching or sacculation of the uterine wall.

Adapted from http://emedicine.medscape.com/article/272497-overview

\section{Figure 2:}

Magnetic resonance images at 22 weeks' gestation (sagittal view). The cervix is elongated and anteriorly displaced behind the pubic symphysis and bladder. The sacculation of the uterus contains the fetal head, which is incarcerated in the pouch of Douglas

Table I: Case reports of recurrent sacculation of the uterus that have been reported in the literature (chronologically, up to August 2009). 